\title{
The Multifaceted Engagement of the Dermatologist in the Covid-19 Pandemic
}

\author{
Boutros Soutou $^{1,2}$ (D) $\cdot$ Roland Tomb ${ }^{1}$ \\ Accepted: 17 July 2020 / Published online: 22 July 2020 \\ (C) Springer Nature Switzerland AG 2020
}

\begin{abstract}
Dermatologists worldwide are engaged in the struggle against Covid-19. They limited their daily activity to priority cases, intending to reduce the exposure of patients in the waiting room. Teledermatology was recommended as an efficient alternative to assure patients' needs and safety. At the same time, dermatologists had to manage the skin injuries of frontline healthcare workers; to characterize the cutaneous manifestations of Covid-19; to assess the optimal treatment of patients with skin diseases, especially those taking immunomodulating and immunosuppressant molecules; and finally to promote balanced precautions in healthy persons.
\end{abstract}

Keywords Teledermatology $\cdot$ Dermatitis $\cdot$ Covid-19 $\cdot$ Cutaneous manifestations

Confronted with the severity of the epidemic, the medical community is joining forces to halt the spread of the virus and the dermatologists worldwide are engaged in the struggle. They are committed during this health crisis to assist their frontline colleagues in their battle in hospitals, and to reduce their activity without compromising the safety of their patients.

\section{The Dermatologist's Medical Activity}

Given the risk of exposure to high numbers of patients in consulting rooms as well as the possibility of contagion coming from healthy carriers, dermatologists had to cancel the non-urgent appointments, screening through a questionnaire and body temperature measurement being insufficient $[1,2]$. Visits for severe eruptions, cancer screening and surveillance,

This article is part of the Topical Collection on Covid-19

Boutros Soutou

boutros.soutou@usj.edu.lb

Roland Tomb

roland.tomb@usj.edu.lb

1 Dermatology Department, School of Medicine, Université Saint-Joseph, Beirut, Lebanon

2 Hôtel-Dieu de France Hospital, Achrafieh, Bvd Alfred Naccache, Beirut 16-6830, Lebanon and urgent skin biopsies were however maintained. Weighing the oncological risk against the probability of having Covid19 helped some centers select the urgent-to-treat cases of skin cancer [3]. These measures, primarily intended to mitigate the pandemic, finally came through the skeptical patients and highlighted the gravity of the crisis we are experiencing. Likewise, the dermatologists, as well as the trainees, could protect themselves and their relatives from unavailing risks and keep themselves ready to replace the front-line workforce whenever needed. This decrease in activity saved as well much needed protective equipment such as gloves, masks, and disinfectants.

In different countries, teleconsultation platforms were relaunched after streamlining their regulations to meet the demand and the needs for patient care. Transmission of the coronavirus to patients at risk is thus avoided. Nevertheless, access to the dermatologist and continuity of care are ensured [4-6]. The long-awaited benefits of telemedicine began to materialize during this pandemic; the healthcare system is undergoing a permanent change to serve the patients in times of crisis, with a higher quality of care and decreased indirect healthcare costs [7]. Many dermatology centers strove to efficiently integrate teledermatology practice. The measures preceding the virtual visit included instructional videos for technical coaching, photographs of the skin problem sent by the patient to combine the advantages of store-and-forward and synchronous telemedicine visits, and virtual rooming performed by a member of the clinical staff to collect medical history, medications, allergies, and pharmacy [8]. Alternating 
between a telemedicine room and an in-person room helped prevent waiting room crowding, maintain adequate time for disinfecting protocols, and maximize access to care while utilizing the full capacity of the staff [8]. Other challenges in implementing outpatient teledermatology consisted of a poor visual quality particularly when evaluating pigmented lesions, medico-legal liabilities, and privacy issues, for instance, parental consent prior to teledermatology visits with minors, and transfer of patient photos using secured and encrypted services [9]. Reducing Covid-related risks is mandatory in psoriasis patients where videos-calls in combination with high-quality images should substitute for office visits when possible; in the same way, dermatologists should encourage their patients to utilize telemedicine for primary care and specialist visits to control the psoriasis-associated comorbidities [10]. By this same means of communication, health professionals in remote hospitals or retirement homes could be assisted in their management of patients with intercurrent skin conditions. In less developed countries, codified telemedicine has just taken its first steps, but some of the dermatologists there already practice an informal non-paid store-and-forward teledermatology through messaging phone applications. Communication is either with colleagues of other specialties or directly with the patient himself.

In line with the lockdown measures, web conferences and e-learning sessions supplanted in-person staff meetings and conferences.

\section{The Skin of Frontline Healthcare Workers}

The prolonged wearing of personal protective equipment, the increased level of protection, the repetition of hygiene measures, and the stressful environment lead to skin complications in almost all medical personnel $[11,12]$. Medical caps can cause itching from exacerbated seborrheic dermatitis or scalp pain secondary to bacterial occlusion folliculitis. Anti-oiliness or anti-dandruff shampoos can prevent such complications. In severe folliculitis, oral antibiotics may be needed. Masks and protective goggles cause facial irritation at the end of the day, which can progress rapidly to erosions in the areas of friction. Transparent film dressing may help prevent pressure injury. Facial pruritus could be prevented by applying either a moisturizing cream to dry skin or a mattifying gel to oily and acneprone skin. Exacerbation of acne, rosacea, or seborrheic dermatitis is not uncommon, and adequate treatment should not be delayed [13]. Hands irritation is caused by iterative washing, surgical washing, and prolonged wearing of gloves [11, 14]. Contrary to popular belief, hydro-alcoholic solutions do not worsen the dryness of the hands. These are particularly irritated by washing with soap and water more than ten times a day [11]. The latest recommendations from the French Dermatology Society favor the exclusive use of hydro- alcoholic solutions in healthcare services [15]. Only when hands get soiled, they can be washed with a mild soap, never antiseptic, then rinsed with lukewarm water, dried gently with soft tissues, and finally moisturized with an emollient cream $[13,15]$.

\section{Patients with Covid-19}

In the early weeks of the infection's emergence in China, rare data if none were reported about a "rash" occurring in $0.2 \%$ of patients $[16,17]$. After the arrival of the epidemic to Italy, cutaneous manifestations were described in 18 out of 88 patients with Covid-19, consisting of an erythematous rash in 14 patients, a widespread urticaria in 3 patients and chickenpoxlike vesicles in one patient. The skin rash was inaugural in 8 cases. Skin reactions to new drugs were excluded [18]. In early April, dermatologists from various countries in Europe and the Middle East shared on informal networks cases of new skin manifestations similar to chilblain. These lesions were particularly examined on the toes of young subjects otherwise in good health. Viral origin was confirmed in a few cases [19-21]. In children, these benign acral vascular lesions were more frequently reported than viral exanthema [22-24]. Prestigious dermatology organizations have recently established registries to collect more cases of cutaneous manifestations, intending to characterize the skin involvement in Covid-19 patients [25, 26]. Reports published daily are describing further cutaneous manifestations like exanthema with scattered vesicles, erythematous facial eruption, transient livedo, and petechial rash [27-31]. A nationwide case collection in Spain studied 375 cases and proposed a classification of the cutaneous manifestations in Covid-19; vesicular lesions appeared early in the course of the disease; chilblain pattern appeared late, in younger patients, with less severe disease; exanthema and urticaria caused pruritus and were associated with a more severe disease; livedo and necrotic lesions took place in older patients with severe disease and a high mortality risk [32].

\section{Patients Followed for Skin Diseases}

Any patient with an active or uncontrolled skin disease should take strict protective measures, as the damaged skin may facilitate the transmission of the virus through indirect contact [6]. The angiotensin-converting enzyme 2 (ACE2), the receptor for SARS-CoV-2, is expressed in the basal layer of the epidermis, the appendages, and the dermal capillaries [33]. The cutaneous expression level of ACE2 correlated with a local immune signature of interferon response and CD8+ T cells [34]. Patients with skin diseases must theoretically cover the affected areas of their skin, regularly apply an emollient cream, and reduce social contact to the minimum. 
The issue will be more challenging when it comes to patients treated with immunosuppressive or immunomodulatory drugs. Experts worldwide are advising in unison not to interrupt any treatment before consultation with the attending physician. However, we are living in a period of increased medical uncertainty where no objective clinical data are yet available about Covid-19 patients treated with such drugs. Dermatologists have to rely on both the data of adverse events published in clinical trials and the understanding of the physiological mechanism of each molecule. Expert consensuses could also help maintain the highest level of care for the patients [35]. One of many burning examples illustrating such decision-making uncertainty would be the controversy on the discontinuation of immunosuppressive drugs in patients with Covid-19. While immunosuppression increases patient susceptibility to the virus, suspending it may precipitate the cytokine storm described in the severe forms of the disease [36]. Two guiding letters by Lebwohl et al. and Price et al. respectively indicated the known rate of infections in the biologic treatment of psoriasis and weighed the risk of the immunomodulating/immunosuppressant molecules used in dermatology $[37,38]$. Treatment discontinuation should be considered in patients with a Covid-19 diagnosis and in those who are a close contact of confirmed cases [39]. Any consideration about starting, keeping, optimizing, or interrupting such treatments should be based on the individual risk and disease profile of each patient. Another specific recommendation for the management of patients with advanced basal cell carcinomas treated with sonic hedgehog inhibitors came from Italian authors, who favored dose adjustment rather than treatment discontinuation during the Covid-19 pandemic [40]. In a high-epidemic area, 30 adult atopic dermatitis patients treated with dupilumab were screened for Covid-19 around 45 days after the outbreak, and none was infected [41].

\section{Healthy Persons}

The most frequent complaint of healthy individuals is irritation dermatitis of the hands secondary to excessive wash with hot water and antiseptic cleansers. A simple way of prevention would be the regular application of fragrance-free emollient creams. It would also be better to favor lukewarm water, mild soap, and even to substitute the use of hydro-alcoholic solutions for repetitive hand wash [15, 42]. The stress of confinement can trigger the relapse of hitherto well-controlled dermatoses such as chronic pruritus, psoriasis, seborrheic dermatitis, rosacea, and acne. Optimization of treatment is mandatory. Due to the shortage of protective masks in town as in hospitals, the saving use of masks for more than $4 \mathrm{~h}$ has frequently lead to facial skin irritation by the excessive moisture trapped inside. $\mathrm{Yu}$ et al. proposed to fold a paper towel and insert it on the inside. This towel, with some absorbent capacity, can be changed every $30 \mathrm{~min}$ to maintain a low level of humidity [43].

\section{Conclusion}

With the advent of a contactless society, we are all solicited to change our behavior. Nevertheless, it remains crucial to preserve our human relationships, to promote a balanced way of prevention and hygiene, and to ensure our patients' safety.

Authors' Contributions Boutros Soutou wrote the manuscript. Roland Tomb participated in the update and the final review of the text.

Data Availability N/A

Code Availability N/A

\section{Compliance with Ethical Standards}

Conflict of Interest The authors declare that they have no conflict of interest.

Ethics Approval N/A

Consent to Participate N/A

Consent for Publication N/A

\section{References}

1. Chen Y, Pradhan S, Xue S. What are we doing in the dermatology outpatient department amidst the raging of the 2019 novel coronavirus? J Am Acad Dermatol. 2020;82:1034.

2. Kwatra SG, Sweren RJ, Grossberg AL. Dermatology practices as vectors for COVID-19 transmission: a call for immediate cessation of nonemergent dermatology visits. J Am Acad Dermatol. 2020;82: e179-80.

3. Tagliaferri L, Di Stefani A, Schinzari G, Fionda B, Rossi E, Del Regno L, et al. Skin cancer triage and management during COVID19 pandemic. J Eur Acad Dermatol Venereol. 2020;34:1136-9. https://doi.org/10.1111/jdv.16529.

4. Pathoulas JT, Stoff BK, Lee KC, Farah RS. Ethical outpatient dermatology care during the coronavirus (COVID-19) pandemic. J Am Acad Dermatol. 2020;82:1272-3.

5. Lee I, Kovarik C, Tejasvi T, Pizarro M, Lipoff JB. Telehealth: helping your patients and practice survive and thrive during the COVID-19 crisis with rapid quality implementation. J Am Acad Dermatol. 2020;82:1213-4.

6. Tao J, Song Z, Yang L, Huang C, Feng A, Man X. Emergency management for preventing and controlling nosocomial infection of 2019 novel coronavirus: implications for the dermatology department. Br J Dermatol. 2020;182:1477-8. https://doi.org/10.1111/ bjd.19011.

7. Shah P, Gutierrez D, Zampella JG. Teaching lessons from the coronavirus disease 2019 (COVID-19) pandemic in telemedicine. J Drugs Dermatol. 2020;19:677.

8. Cohen JM, Bunick CG, Perkins SH. The New Normal: An approach to optimizing and combining in-person and telemedicine 
visits to maximize patient care. J Am Acad Dermatol. 2020 Jun 25: S0190-9622(20)31173-7. doi: https://doi.org/10.1016/j.jaad.2020. 06.075 .

9. Farshchian M, Potts G, Kimyai-Asadi A, Mehregan D, Daveluy S. Outpatient Teledermatology implementation during the COVID-19 pandemic: challenges and lessons learned. J Drugs Dermatol. 2020;19:683.

10. Chat VS, Uppal SK, Kearns DG, Wu JJ. Clinical management of psoriasis patients during the COVID-19 pandemic. J Dermatolog Treat. 2020 Jun;22:1-2. https://doi.org/10.1080/09546634.2020. 1781045 .

11. Lan J, Song Z, Miao X, et al. Skin damage among healthcare workers managing coronavirus disease-2019. J Am Acad Dermatol. 2020;82:1213-4

12. Pei S, Xue Y, Zhao S, Alexander N, Mohamad G, Chen X, et al. Occupational skin conditions on the frontline: a survey among 484 Chinese healthcare professionals caring for Covid-19 patients. J Eur Acad Dermatol Venereol. 2020. https://doi.org/10.1111/jdv.16570.

13. Yan Y, Chen H, Chen L, Cheng B, Diao P, Dong L, et al. Consensus of Chinese experts on protection of skin and mucous membrane barrier for healthcare workers fighting against coronavirus disease 2019. Dermatol Ther. 2020. https://doi.org/10.1111/ dth. 13310

14. Balato A, Ayala F, Bruze M, Crepy MN, Gonçalo M, Duus JJ. European Task Force on Contact Dermatitis statement on coronavirus 19 disease (COVID-19) outbreak and the risk of adverse cutaneous reactions. J Eur Acad Dermatol Venereol. 2020. https://doi. org/10.1111/jdv. 16557 .

15. Société Française de Dermatologie, 2020. Mesures COVID-19 Prenez soin de vos mains! [www document]. URL https:// evenements-sfd.fr/wp-content/uploads/2020/04/Prenez-soin-devos-mains-Mesures-COVID-19.pdf?utm_source (Accessed on 24 April 2020).

16. Guan WJ, Ni ZY, Hu Y, Liang WH, Ou CQ, He JX, et al. Clinical characteristics of coronavirus disease 2019 in China. N Engl J Med. 2020;382:1708-20. https://doi.org/10.1056/NEJMoa2002032.

17. Fu L, Wang B, Yuan T, Chen X, Ao Y, Fitzpatrick T, et al. Clinical characteristics of coronavirus disease 2019 (COVID-19) in China: a systematic review and meta-analysis. J Inf Secur. 2020;80:656-65. https://doi.org/10.1016/j.jinf.2020.03.041.

18. Recalcati S. Cutaneous manifestations in COVID-19: a first perspective. J Eur Acad Dermatol Venereol. 2020;34. https://doi.org/ 10.1111/jdv.16387.

19. Kolivras A, Dehavay F, Delplace D, Feoli F, Meiers I, Milone L, et al. Coronavirus (COVID-19) infection-induced chilblains: a case report with histopathological findings. J Am Acad Dermatol Case Reports. 2020. https://doi.org/10.1016/j.jdcr.2020.04.011.

20. Alramthan A, Aldaraji W. A case of COVID-19 presenting in clinical picture resembling chilblains disease. First report from the Middle East. Clin Exp Dermatol. 2020 https://doi.org/10.1111/ ced.14243.

21. Bouaziz JD, Duong T, Jachiet M, Velter C, Lestang P, Cassius C, et al. Vascular skin symptoms in COVID-19: a french observational study. J Eur Acad Dermatol Venereol. 2020. https://doi.org/10. 1111/jdv.16544.

22. Morey-Olivé M, Espiau M, Mercadal-Hally M, Lera-Carballo E, García-Patos V. Cutaneous manifestations in the current pandemic of coronavirus infection disease (COVID 2019). An Pediatr (Engl Ed). 2020. https://doi.org/10.1016/j.anpede.2020.04.002.

23. Recalcati S, Barbagallo T, Frasin LA, Prestinari F, Cogliardi A, Provero MC, et al. Acral cutaneous lesions in the time of COVID-19. J Eur Acad Dermatol Venereol. 2020. https://doi.org/ 10.1111/jdv.16533.

24. Colonna C, Monzani NA, Rocchi A, Gianotti R, Boggio F, Gelmetti C. Chilblains-like lesions in children following suspected
Covid-19 infection. Pediatr Dermatol. 2020;37:437-40. https://doi. org/10.1111/pde.14210.

25. Freeman EE, McMahon DE, Fitzgerald ME, Fox LP, Rosenbach M, Takeshita J, et al. The AAD COVID-19 Registry: crowdsourcing dermatology in the age of COVID-19. J Am Acad Dermatol. 2020;83:509-10. https://doi.org/10.1016/j.jaad.2020.04. 045.

26. Société Française de Dermatologie, 2020. Covid-19 et lésions cutanées -point d'étape COVIDSKIN de la SFD [www document]. URL https://evenements-sfd.fr/?mailpoet router\&endpoint (Accessed on 24 April 2020).

27. Marzano AV, Genovese G, Fabbrocini G, Pigatto P, Monfrecola G, Piraccini BM, et al. Varicella-like exanthem as a specific COVID19-associated skin manifestation: multicenter case series of $22 \mathrm{pa}-$ tients. J Am Acad Dermatol. 2020;83:280-5. https://doi.org/10. 1016/j.jaad.2020.04.044.

28. Joob B, Wiwanitkit V. COVID-19 can present with a rash and be mistaken for dengue. J Am Acad Dermatol. 2020;82:e177. https:// doi.org/10.1016/j.jaad.2020.03.036.

29. Zhang JJ, Dong X, Cao YY, Yuan YD, Yang YB, Yan YQ, et al. Clinical characteristics of 140 patients infected with SARS-CoV-2 in Wuhan, China. Allergy. 2020;75:1730-41. https://doi.org/10. 1111/all.14238.

30. Henry D, Ackerman M, Sancelme E, Finon A, Esteve E. Urticarial eruption in COVID-19 infection. J Eur Acad Dermatol Venereol. 2020;34:e244-5. https://doi.org/10.1111/jdv.16472.

31. Sachdeva M, Gianotti R, Shah M, Lucia B, Tosi D, Veraldi S, et al. Cutaneous manifestations of COVID-19: report of three cases and a review of literature. J Dermatol Sci. 2020 https://doi.org/10.1016/j. jdermsci.2020.04.011.

32. Galván Casas C, Català A, Carretero Hernández G, RodríguezJiménez P, Fernández Nieto D, Rodríguez-Villa LA. Classification of the cutaneous manifestations of COVID-19: a rapid prospective nationwide consensus study in Spain with 375 cases. Br J Dermatol. 2020;183:71-7. https://doi.org/10.1111/bjd.19163.

33. Hamming I, Timens W, Bulthuis MLC, Lely AT, Navis GJ, Goor H Van. Tissue distribution of ACE2 protein, the functional receptor for SARS coronavirus . A first step in understanding SARS pathogenesis. J Pathol 2004;203:631-637.

34. Li MY, Li L, Zhang Y, Wang XS. Expression of the SARS-CoV-2 cell receptor gene ACE2 in a wide variety of human tissues. Infect Dis Poverty. 2020;9:45.

35. Freeman EE, McMahon DE. Creating dermatology guidelines for Covid-19: the pitfalls of applying evidence based medicine to an emerging infectious disease. J Am Acad Dermatol. 2020;82:e2312. https://doi.org/10.1016/j.jaad.2020.04.002.

36. Shah P, Zampella JG. Use of systemic immunomodulatory therapies during the coronavirus disease 2019 (COVID-19) pandemic. J Am Acad Dermatol. 2020;82:e203-4. https://doi.org/10.1016/j. jaad.2020.03.056.

37. Lebwohl M, Rivera-Oyola R, Murrell DF. Should biologics for psoriasis be interrupted in the era of COVID-19? J Am Acad Dermatol. 2020;82:1217-8.

38. Price KN, Frew JW, Hsiao JL, Shi VY. COVID-19 and immunomodulator/immunosuppressant use in dermatology. J Am Acad Dermatol. 2020;82:e173-5.

39. Torres T, Puig L. Managing cutaneous immune-mediated diseases during the COVID-19 pandemic. Am J Clin Dermatol. 2020. https://doi.org/10.1007/s40257-020-00514-2.

40. Villani A, Fabbrocini G, Costa C, Scalvenzi M. Patients with advanced basal cell carcinomas in treatment with sonic hedgehog inhibitors during the coronavirus disease 2019 (COVID-19) period: management and adherence to treatment. J Am Acad Dermatol. 2020;82:e205. https://doi.org/10.1016/j.jaad.2020.03.057.

41. Carugno A, Raponi F, Locatelli AG, Vezzoli P, Gambini DM, Di Mercurio M. No evidence of increased risk for COVID-19 infection 
in patients treated with Dupilumab for atopic dermatitis in a highepidemic area - Bergamo, Lombardy, Italy. J Eur Acad Dermatol Venereol. 2020. https://doi.org/10.1111/jdv.16552.

42. Cavanagh $\mathrm{G}$, Wambier C. Rational hand hygiene during COVID19 pandemic. J Am Acad Dermatol. 2020;82:e211. https://doi.org/ 10.1016/j.jaad.2020.03.090.
43. Yu N, Wu L, Su J, Huang K, Zhao S, Chen X. One more paper towel, longer protection. J Am Acad Dermatol. 2020;82:e189-90. https://doi.org/10.1016/j.jaad.2020.03.064.

Publisher's Note Springer Nature remains neutral with regard to jurisdictional claims in published maps and institutional affiliations. 